\title{
Evaluation of An Online Learning Concept For Nursing Students In Caring For Patients With Dementia: Results of A Questionnaire Survey
}

Adina Dreier-Wolfgramm ( $\square$ adina.dreier-wolfgramm@haw-hamburg.de )

University of Applied Science (HAW) Hamburg

Anja Teubner

University of Applied Science (HAW) Hamburg

Katrin Kern

University of Applied Science (HAW) Hamburg

\section{Research Article}

Keywords: Nursing education, distance learning, nursing education research, dementia

Posted Date: October 14th, 2021

DOl: https://doi.org/10.21203/rs.3.rs-960357/v1

License: (c) (i) This work is licensed under a Creative Commons Attribution 4.0 International License.

Read Full License 


\section{Abstract}

Background: Dementia is a major public health concern. Nurses have a key role in caring for patients with dementia and to relieve caregivers. To prepare them for adequate demand-oriented nursing care provision, there is a need for training and education. Due to the current Covid-19 pandemic, an online course with focus on a health care need assessment was developed.

Methods: The Elaine Study is a quantitative study using questionnaire-based interviews. The recruitment of nursing students for the study was guided by following inclusion criteria (a) second-year nursing students participating in the module 'caring for elderly patients', (b) less than three missing lectures. Of all nursing students $(\mathrm{N}=127), \mathrm{n}=48$ met the inclusion criteria. Twenty-eight students participated.

Quantitative data were analyzed by descriptive statistics. For analyzing possible relations between lectures evaluations aspects among each other, the Spearman correlation was used. Collected qualitative data were analyzed by the Kuckartz suggested qualitative content analysis using the software MAXQDA.

Results: Nursing students judged the overall course structure as very well (M 1.36, SD 0.48). Learning aims were clear defined (M 1.61, SD 0.68), learning contents have been properly demonstrated (M 1.68, SD 0.67) and teaching methods contribute the understanding (M 1.63, SD 0.62). The exercise on the Geriatric Assessment promote the internal learning process (M 1.67, SD 1.00) and the final online simulation training made lecture contents easier to understand (M 1.86, SD 0.89). Correlation were determined among the course structure and the (1) clear definition of learning aims $\left(r^{\mathrm{Sp}} 0.566, p=0.002\right)$, (2) presentations and references are made available ( $\left.r^{\mathrm{Sp}} 0.514, \mathrm{p}=0.005\right)$, (3) teaching methods contribute the understanding $\left(r^{S p} 0.535, p=0.004\right)$ and $(4)$ an increase of individual learning ability $\left(r^{S p} 0.573\right.$, $\mathrm{p}=0.001$ ). Implication for improvement proposes a reduction of nursing students team members from four or five to a work in teams of two nursing students.

Conclusions: The Elaine study describes the feasibility of an online learning concept for nursing students in caring for patients with dementia. To identify actual impact on patient's health and on caregiver burden as well, further studies are needed.

\section{Background}

Dementia is a major public health concern in the older population. Currently, about 50 million patients are living with dementia worldwide. According to forecasts, the number will increase to more than 130 million patients infected by this disease until 2050. (1) The majority of patients live in the community in their own households. (1) As a result, various dementia care models have been developed for primary health care, which can be summarized as 'collaborative care' or 'patient-centered care'. It focuses on long-term systematic approaches to improve management of the dementia disease rather than on treating acute symptoms. (2) The aim is to address patients' and caregivers' complex healthcare needs and to enable multidisciplinary care. (3-5) Nurses have a key role in caring for patients with dementia and to relieve caregivers. To prepare them for adequate demand-oriented nursing care provision and for successful 
collaboration with other health care professionals, there is a need for training and education. (6) An analysis of present nursing training shows, that dementia is becoming an important topic in nursing curricula. Nevertheless, it still focus on treating specific symptoms (e.g. challenging behavior) (7) as well as on diagnostic (8) and providing end-of-life care $(9,10)$. Programs are characterized by inconsistency and gaps in professional dementia education (11). Therefore, evidence suggests deficits in knowledge of dementia and inadequate skills in key elements in dementia care. (12) Nursing dementia care begins with a systematic assessment of specific needs for health care services and counseling issues. Though there is a variety of nursing students trainings options related to dementia, none of these focus on the systematic assessment for health care needs for the patients. To overcome this lack, a learning concept for nursing students was developed. Due to the current Covid-19 pandemic, face-to-face lectures and clinical training by simulation with simulations patients is a challenge. (13-15) Therefore, the concept is designed for an online course using the Microsoft Teams platform.

\section{Online learning concept for nursing students}

It addresses exciting nursing care services for elderly patients and the systematic assessment of health care needs of the patients with dementia by using the so-called Geriatric Assessment. The online learning concept take one semester and is part of the module 'Caring for elderly patients' in the seven-semester nursing program at the Department Nursing and Management of the University of Applied Science (HAW) Hamburg. It comprises following lectures: (a) four theoretical lectures in caring for elderly patients with dementia and the Geriatric Assessment, (b) exercise of Geriatric Assessment and (c) online simulation training (see Figure 1).

The four theoretical lectures dealt in detail with specifics in caring for elderly patients and patients with dementia as well as with settings and nursing health care service existing for this patient groups. This was followed by an introduction of the Geriatric Assessment. The nursing students become more familiar to the Geriatric Assessment concept including the relevant assessment instruments. Afterwards, the students comprehensively exercise the usage of the Geriatric Assessment instruments by themselves in groups of four to five students. During the exercise, students taking patients and interviewer perspective, test the time required for the implementation and identify potential challenges for the online conduction. Subsequently, the online simulation training was prepared by student's decision, who perform and who observe the online simulation training, and which assessments instruments are suitable for the online interview with the patient with dementia to identify specific health care needs. The patient with dementia was a simulation patient performed by a professional actor, who completed a nursing education program as well. Students systematically identify health care needs in following aspects: (a) activities of daily living (Barthel Index, IADL), (b) cognition (MMSE, clock test), (c) psychological state (GDS), (d) social situation, (e) mobility and risk of falling, (f) nutritional status (MNA) and (g) incontinence. The results of the online assessment provide the basis for the nursing students to develop a health care plan for the patient with dementia. 
Currently, there is less knowledge about online nursing education programs focusing on the assessments of health care needs of patients with dementia. To specify the impacts of the online learning concept, the Elaine study (Evvaluation of a nursing simulation learning concept caring for patients with dementia) was conducted. It addressed following research question: How evaluate nursing students the online learning concept with regard to (a) the theoretical lectures, (b) the exercise on the Geriatric Assessment and the (c) online simulation training to assess patient's health care needs?

\section{Methods}

\section{Design}

The present analyses are based on data derived from the Elaine Study, which is a quantitative study using questionnaire-based interviews. The aim was to examine the feasibility of the online education concept as well as to identify strength and weakness to provide an optimized online education nursing program in the future.

\section{Participants}

The recruitment of nursing students for the study was guided by following inclusion criteria (a) secondyear nursing students participating in the module 'caring for elderly patients', (b) less than three missing lectures. Both criteria were chosen to ensure that nursing students were enrolled in the study, who currently undergo the course with the recent developed online format for the first time. Hereinafter, it was important that student receive an overall impression of the whole online education program. This require an almost completely attendance of the course. Of all nursing students $(\mathrm{N}=127), \mathrm{n}=48$ met the inclusion criteria. At the beginning of the 2021 summer semester, students were informed about the Elaine study in the first lecture by the PI of the study. Students received the opportunity to ask questions with regard to the design and the order of the study. When students express an interest in participation, a mailed written project information and a mailed written informed consent was delivered by the PI. Then, students had 14 days to decide for participation in the study. If the completed and signed written informed consent were sent per Mail to the $\mathrm{Pl}$, students were enrolled in the Elaine study $(\mathrm{n}=28)$. Twenty students rejected their participation. Reasons for non-participation provided included: (a) lack of time $(n=15)$, (b) being in prepetition for upcoming examinations $(n=4)$ and stay abroad during the data collection phase $(n=1)$. Over the course of the study none of the students dropped out. The majority of students were female $(n=25 ; 89.3 \%)$ and more than the half $(53.6 \%)$ had professional experience in caring for patients with dementia before the course just had begun (see Table 1).

The average age was 21.85 years (SD 2.83). Almost $90 \%(n=25)$ of the students participated in all lectures of the module.

Data measurement 
It is one of the first exploration of an evaluation for an online nursing education program focusing on the systematic assessment of health care needs for patients with dementia. No valid and reliable instrument of a standardized questionnaire was available. Therefore, a questionnaire was developed. It based on existing evaluation instruments for academic education programs and online lectures evaluation instruments from the Philipps University of Marburg. The quantitative mailed questionnaire consisted of three dimensions: (a) Theoretical introduction in nursing health care services and the Geriatric Assessment (Lectures evaluation 10 items, Docent evaluation 11 items), (b) Exercise of the Geriatric Assessment (10 items), (c) Online simulation training (online simulation training by MS Teams 21 items, Docent evaluation 3 items, Simulation patient evaluation 9 items). A five-point Likert scale with the response categories ' $1=$ strongly agree', ' $2=$ partly agree', ' $3=$ neither nor', ' $4=$ =partly disagree', ' $5=$ disagree' were used. The instrument ended with semi-structured question with respect to positive aspects and implications for improvement as well as for socio-demographic data (age, gender, number of students missing lectures, professional experience in caring for patients with dementia).

The survey instrument was pretested in a small group with representatives of the target group ( $N=6$ nursing students, $n=3$ female), who have not been participating in the subsequent data collection. The aim was to identify the acceptance and practicability of the questionnaire, the clarity of the questions and answer categories as well as to determine suggesting lack of relevant issues. The pretest was carried out by a mailed questionnaire to the participants. They completed the questionnaire by themselves and made written notes in the document. The completed instruments were sent to the study center. Two study member (AT, KK) analyzed written notes and made adaptions concerning linguistic changes and individual terms. Comprehensive adjustments with regard to size reduction, response format or structural changes were not required. Finally, the questionnaire consists of three dimensions with 74 items, which was used for the subsequent quantitative survey. Missing values occurred less frequent $(<5 \%)$. It demonstrating a satisfactory acceptability of the questionnaire.

\section{Data collection}

The data collection was carried out between May and June 2021. In total, 48 questionnaires were sent to nursing students after completing the whole course at the end of the 2021 summer semester. All students receive the questionnaire per mail at the end of May and completed the questionnaire by themselves until the end of June 2021. The completion took $15-20 \mathrm{~min}$. The completed questionnaires were sent back to the study center at the University of Applied Science (HAW) Hamburg by 28 nursing students.

\section{Data analysis}

For analysis, the data were verified and documented in a pdf-data base and then transferred to the software SPSS (IBM Statistics 26, 2020). The quantitative data of the mailed questionnaire were analyzed by descriptive statistics. To identify relations between lectures evaluation and the professional experiences of students in caring for patients with dementia, the $\mathrm{Chi}^{2}$ Test was used. For analyzing 
possible relations between lectures evaluations aspects among each other, the Spearman correlation was used.

Collected qualitative questionnaire-based data from semi-structured questions regarding positive aspects and implications for improvement were transcribed and analyzed by the Kuckartz suggested qualitative content analysis using the software MAXQDA Version 20.4.1 (VERBI GmbH, Berlin). Two study team members (ADW, AT) coded semi-structured interviews questions according to the consensual coding approach. First, both team members coded separately. Then, resulting two category systems were compared for similarities and differences. In case of differences, the codes were discussed within the whole study team (ADW, AT, KK) and modified if all team members agreed. This approach caused an extension of the category system. In conclusion, a system with categories, sub-categories and codes based on the code systems of both coders was developed.

\section{Results}

\section{Course structure and docent evaluation}

Generally, it can be observed that students judged the overall course structure as very well (M 1.36, SD 0.48) (see Table 2). Learning aims were clear defined ( $M$ 1.61, SD 0.68), learning contents have been properly demonstrated (M 1.68, SD 0.67) and teaching methods contribute the understanding (M 1.63, SD $0.62)$. The majority of nursing students 'partly agree' ( $n=17 ; M 2.21, S D 0.99)$, that the increase of individual learning ability is high and there is an increase interest in caring for patients with dementia (M 2.32, SD 1.09) (see Table 2).

No significance evidence was found between student's course structure evaluation and their former professional experience in caring for patient with dementia by $\mathrm{Chi}^{2}$ Tests. In contrast, specific course evaluation aspects among each other have significant associations (see Table 3). Four positive correlation were determined among the course structure and the (1) clear definition of learning aims $\left(r^{S p} 0.566, p=0.002\right),(2)$ presentations and references are made available $\left(r^{S p} 0.514, p=0.005\right),(3)$ teaching methods contribute the understanding $\left(r^{S p} 0.535, p=0.004\right)$ and $(4)$ an increase of individual learning ability ( $\left.r^{\mathrm{Sp}} 0.573, \mathrm{p}=0.001\right)$. In addition, there is numerous positive correlations between clear defined learning aims and presentations and references, which are made available $\left(r^{S p} 0.619, p=0.000\right)$ as well as between learning contents, which had been dealt with appropriate pace and the (1) increase of individual learning ability $\left(r^{S p} 0.632, p=0.000\right),(2)$ the up-to-date teaching contents were $\left(r^{S p} 0.588\right.$, $p=0.002)$ and $(3)$ the increases of interest in caring for patients with dementia $\left(r^{S p} 0.594, p=0.001\right)$.

The majority of docent evaluation results were highly positive (see Table 4). This is particularly evident regarding the structured teaching ( $M$ 1.21, SD 0.41), dealing with students' kind and open-minded ( $M$ $1.11, S D 0.42)$ as well as in examining issues and suggestions ( $M 1.14$, SD 0.35). 
Furthermore, docent was able to making complicated contents understandable (M 1.64, SD 0.67), gave helpful feedback to nursing students' statements (M 1.21, SD 0.49) and clarified benefits and usability of learning contents (M 1.57, SD 0.69). Therefore, interesting lectures were designed ( $M$ 1.86, SD0.93). However, study results appear that encouragement to critical discussions does not yet sufficiently takes place in lectures (M 2.15, SD 1.02). In contrast, docent was readily available for further questions ( $M$ 1.36, SD 0.56).

\section{Exercise on Geriatric Assessment}

Table 5 highlights nursing students evaluations results on the Geriatric Assessment exercise, which shows that students judged it predominant as positive. It had a clearly defined structure (M 1.50, SD 0.51 ), took previous knowledge up ( $M 1.68, S D$ 0.77) and therefore, promote the internal learning process (M 1.67, SD 1.00). Along with the rating that the Geriatric Assessment had sufficient time (M 1.21, SD 0.41 ), nursing students concluded a change in the nursing students' interest for lecture's topic and an enhancement of abilities to carry out learning contents in nursing care practice (see Table 5).

Significant positive correlation results were found between the promotion of the internal learning process and the enhancement of previous knowledge $\left(r^{S P} 0.590, p=0.001\right)$. Negative significant correlation exits for the promotion of the internal learning process and students' abilities to carry out contents in practice $\left(r^{S P}-0.554, p=0.003\right)$.

\section{Online simulation training}

For the following final online simulation training to assess health care needs for the patient with dementia, nursing students illustrated both, positive and negative aspects of these learning format (see Table 6). Students stated positive a clear defined structure (M 1.39, SD 0.56), a sufficient time for the online simulation training (M 1.08, SD 0.27) and that it took previous knowledge up (M 1.92, SD 0.93). The support of the online simulation format to made lecture contents easier to understand was mostly evaluated as 'partly agree' (M 1.86, SD 0.89 ). On the contrary, the aim to provide specific practical skills, enhance the understanding in complex issues and to increase nursing students learning motivation was partially achieved (see Table 6). Nursing students evaluate these three aspects predominantly with 'neither nor'.

Positive significant evidence was found for the correlation between the aspect, that the online simulation training increase of nursing students learning motivation when (1) took previous knowledge up ( $\mathrm{r}^{\mathrm{Sp}} 0.533$, $p=0.004)$ as well as for made lecture contents easier to understand $\left(r^{S p} 0.536, p=0.004\right)$.

\section{Positive aspects and implications for improvement}

Nursing students mentioned more positive aspects than implications for improvement. The following positive statements were made with respect to (1) the lectures structure, (2) the self-determined learning, (3) the docent and the (4) online simulation training. The structure of the course and their order in (a) 
theoretical lectures, (b) exercise and (c) online simulation training were described as very positive. Schedule planning without feeling to learn under time pressure had been highly positive rated. Therefore, a pleasant learning atmosphere have been successfully implemented. Single lectures were well prepared. Course contents varying better balanced the previously known lectures structure, consisting of classroom teaching and self-study. The possibility to present former practical experience and to compare them among the student's group was stated as positive as well.

Therefore, a nursing student concluded: '...lectures organization was very well. We always knew, what the next steps are and we were able to manage weekly work assignments.'(FB 0002:7-8)

The opportunity to exercise the usage of the Geriatric Assessment is a further positive aspect to student's mind. It enabled learning with own pace chosen and allows a further individual occupation with learning contents as well as it promotes a growing interest in caring for patients with dementia. The docent kindness towards nursing students, the given opportunity to address requests for further lecture information's and the mutual sharing of former professional practice experiences in caring for patients with dementia were positively emphasized by nursing students. For the online simulation training, nursing students felt well prepared by the theoretical lectures. Besides, they were allowed sufficient time for the preparation.

Therefore, nursing students appreciate the opportunity to test their own skills ,... without any pressure... . I was shown my own practical competences clear and current existing deficits as well.'(FB 0030: 64-65)

The use of a simulation patient has been very appreciated and increases the practical applications.

In conclusion, a nursing student summarized to be '... well prepared for the first practical experience in caring for elderly patients and knowledge taken from the lecture will requisite safety in handling with this patient group.' (FB 0043:73-75)

Major challenges remain in technical reasons (e.g. poor internet connections). Online discussions had been difficult to implement and a student indicates, that some students participate inadequate in lectures.

This nursing student therefore concludes, that '... a remarkable difference is noticeable between the classroom learning and the online education.'(FB 0015: 116.117)

It resulted among other things in the inability to apply the Geriatric Assessment instruments. Therefore, a nursing student proposes a reduction of nursing students team members from four or five to a work in teams of two nursing students.

\section{Discussion}

The Elaine Study aimed to examine the feasibility of the online course concept and to identify strength and weakness. Overall, nursing students confirm the feasibility and stated an increase of individual learning ability and enhanced interest in caring for patients with dementia. Bickford et al. reported similar 
results and concluded that nursing students had a broad understanding in dementia. (7) They gained substantial knowledge and understand the importance of early disease detection and needs-based treatment. (16) Other study results showed an increase in students' positive attitudes towards caring for patients with dementia. Thereby, students age, their academic year, previous training and practical care experiences in caring for patients with dementia have an beneficial influence on their positive attitudes. (17) Subsequently, students developed an increased confidence in caring for persons with dementia after completing specific education program with focus in dementia. $(18,19)$ Strengthening nursing students' self-efficacy was described by Takeuchi et al. (20) In the long run, a positive contribution for the improvement in dementia care can be expected. (7)

Due to the current Covid-19 pandemic there is a huge challenge to the education system. In the majority, most lectures were delivered fully online. The online education course of the Elaine Study showed that nursing students were satisfied with the online education program. $\mathrm{Li}$ et al reinforces these findings and identify key factors that affected the student's attitudes to online education. It contains (a) teachers' professional title, (b) students' year of study and the (c) location of current residence. (14) Additional factors have been identified and comprise the (1) choice of online teaching mode, (2) the platform or technology, (3) faculty preparedness, as well as (4) the learner motivation and expectations. (15) Supplementary evaluation results of the Elaine study demonstrated that there was no influence between student's course evaluation and the former professional experience in caring for patient with dementia. For this purpose, Swaminathan et al described the willingness of students to learn through online and concluded that students' previous experiences with online learning courses, and the perceived advantages might influence nursing student's readiness. (21)

For the online simulation training nursing students emphasized that they like to had sufficient time. In consequence it took students previous knowledge up. Schedule planning without feeling to learn under time pressure had been rated highly positive. Using the online format for the simulation training supports the aim to made lecture contents easier to understand. Further advantages of this approach are described by Taylor et al. They reported an online simulation training experience have no risk to patient safety. (22) Nursing students of the Elaine study confirm these results and mentioned highly positive the possibility to learn without any pressure and appreciate receiving the opportunity to exercise own practical competences as well as to identify current existing deficits in a securely learning environment. As a complement, Meyer et al find comparable result based on their study including that an online simulation training enhances traditional teaching methods and helps students to understand the experiences of people living with dementia. Furthermore, it inspired students to reflect on actions during the simulation training. (23) Nursing students of the Elaine study therefore summarized to felt better prepared for upcoming practical experiences. In consequence, Meyer et al propose a modified transformative learning process for dementia simulation training for healthcare students to create the best possible prerequisites for optimum dementia care in the future. (23) In the opinion of Taylor et al., these mentioned advantages are important fundamentals to enhance the learning experience and to create effective, efficient clinicians in the future. (22) 
The Elaine Study has limitations. First, the use of purposive sampling for the nursing students can be highly prone to selection bias. The definition of clear inclusion criteria should antagonize this potential bias. Second, no standardized questionnaire was available. Therefore, a questionnaire was developed. It based on existing evaluation instruments for academic education programs and online lectures evaluation instruments from the Philipps University of Marburg. In addition, a pretest was conducted, which result in in linguistic adaptions but no comprehensive adjustments were needed. Nevertheless, generalization to the whole nursing student population is limited.

\section{Conclusions}

The Elaine study describes the feasibility of an online learning concept for nursing students in caring for patients with dementia with focus on the assessment of health care needs. Students judged the overall course structure as very well and appreciate the opportunity for online simulation training with great potential as an alternative learning method during the corona pandemic. Therefore, nursing students' interest in caring for patients with dementia increased as well as the individual learning ability. A sustainable implementation of the online learning format faces various barriers, including particularly technical reasons, inadequate participation of some students and the limited opportunities to implement specific learning methods (e.g. online discussions). In consequence, further studies with a greater number of nursing students is needed to identify facilitators for students learning outcome in more details. The actual impact on patient's health and on caregiver burden as well as on the student's professional competence need to be studied in controlled prospective designs in the future.

\section{List Of Abbreviations}

Elaine Study: Evaluation of a nursing simulation learning concept caring for patients with dementia

\section{Declarations}

Ethics approval and consent to participate. Research and methods were performed in accordance with the Declaration of Helsinki and all relevant guidelines and regulations. Ethical approval was obtained for the study from the Ethic Committee of the Competence Centre Health of the University of Applied Science (HAW) Hamburg (reference number: 2021-12). Written informed consent was obtained from enrolled participants.

\section{Consent for publication:}

Not Applicable.

Availability of data and materials: The datasets used and analysed during the current study are available from the corresponding author Adina Dreier-Wolfgramm (adina.dreier-wolfgramm@haw-hamburg.de).

Competing interests: The authors declare that they have no competing interests. 
Funding: The study was funded by the University of Applied Science (HAW) Hamburg. AT and KK received financial support for their time as a Research Assistant.

Authors' contributions: ADW as the PI of the study developed the study design and made substantial contributions to recruitment of students, data collection, data management, data analysis, data interpretation and drafting the manuscript. AT made substantial contribution in pretesting the questionnaire, data interpretation and critically reviewed the manuscript. KK were involved in pretesting the questionnaire, data interpretation and critical review of the manuscript. All authors read and approved the final manuscript.

Acknowledgements: The authors acknowledge the support of the University of Applied Science (HAW) Hamburg, which enabled the Elaine Study and support the article processing charge by the Open Access Publication Fund of Hamburg University of Applied Sciences. Furthermore, special thanks to the participating nursing students, who have provided the grounds to the success of the study.

\section{Literature}

1. Alzheimer's Disease International. World Alzheimer Report 2015. The Global Impact of Dementia. An analysis of prevalence, Incidence, cost and trend. London2015.

2. Dreier-Wolfgramm A, Michalowsky B, Austrom MG, van der Marck MA, lliffe S, Alder C, et al. Dementia care management in primary care : Current collaborative care models and the case for interprofessional education. Z Gerontol Geriatr. 2017;50(Suppl 2):68-77.

3. LaMantia MA, Alder CA, Callahan CM, Gao S, French DD, Austrom MG, et al. The Aging Brain Care Medical Home: Preliminary Data. J Am Geriatr Soc. 2015;63(6):1209-13.

4. Austrom MG, Carvell CA, Alder CA, Gao S, Boustani M, LaMantia M. Workforce development to provide person-centered care. Aging Ment Health. 2016;20(8):781-92.

5. Reilly S, Miranda-Castillo C, Malouf R, Hoe J, Toot S, Challis D, et al. Case management approaches to home support for people with dementia. Cochrane Database Syst Rev. 2015;1(1):Cd008345.

6. Dreier A, Thyrian JR, Eichler T, Hoffmann W. Qualifications for nurses for the care of patients with dementia and support to their caregivers: A pilot evaluation of the dementia care management curriculum. Nurse Educ Today. 2016;36:310-7.

7. Bickford B, Daley S, Sleater G, Hebditch M, Banerjee S. Understanding compassion for people with dementia in medical and nursing students. BMC Med Educ. 2019;19(1):35.

8. Zullo AR, Danko KJ, Moyo P, Adam GP, Riester M, Kimmel HJ, et al. AHRQ Comparative Effectiveness Technical Briefs. Prevention, Diagnosis, and Management of Opioids, Opioid Misuse, and Opioid Use Disorder in Older Adults. Rockville (MD): Agency for Healthcare Research and Quality (US); 2020. 
9. Midtbust MH, Alnes RE, Gjengedal E, Lykkeslet E. Perceived barriers and facilitators in providing palliative care for people with severe dementia: the healthcare professionals' experiences. BMC Health Serv Res. 2018;18(1):709.

10. Nguyen CM, Jansen Bde W, Hughes CM, Rasmussen W, Weckmann MT. A qualitative exploration of perceived key knowledge and skills in end-of-life care in dementia patients among medical, nursing, and pharmacy students. J Palliat Med. 2015;18(1):56-61.

11. Grosvenor W, Gallagher A, Banerjee S. Reframing dementia: Nursing students' relational learning with rather than about people with dementia. A constructivist grounded theory study. Int J Geriatr Psychiatry. 2021;36(4):558-65.

12. Eccleston CE, Lea EJ, Mclnerney F, Crisp E, Marlow A, Robinson AL. An investigation of nursing students' knowledge of dementia: A questionnaire study. Nurse Educ Today. 2015;35(6):800-5.

13. Jallad ST, Işık B. Transitioning Nursing Students' Education from Traditional Classroom to Online Education during the COVID-19 Pandemic: A Case Study Applied to the Meleis Trial. Florence Nightingale J Nurs. 2021;29(1):124-7.

14. Li W, Gillies R, He M, Wu C, Liu S, Gong Z, et al. Barriers and facilitators to online medical and nursing education during the COVID-19 pandemic: perspectives from international students from low- and middleincome countries and their teaching staff. Hum Resour Health. 2021;19(1):64.

15. Madhavanprabhakaran G, Francis F, John SE, Al Rawajfah O. COVID-19 pandemic and remote teaching: transition and transformation in nursing education. Int J Nurs Educ Scholarsh. 2021;18(1).

16. Matsuda Y, Hashimoto R, Takemoto S, Yoshioka Y, Uehara T, Kawasaki Y. Educational benefits for nurses and nursing students of the dementia supporter training program in Japan. PLoS One. 2018;13(7):e0200586.

17. Scerri A, Scerri C. Nursing students' knowledge and attitudes towards dementia - a questionnaire survey. Nurse Educ Today. 2013;33(9):962-8.

18. Long EM, Hale RL. Improving nursing students' confidence in caring for persons with dementia. Geriatr Nurs. 2021.

19. Mastel-Smith B, Kimzey M, He Z. Dementia Care Education for Nursing Students. J Nurs Educ. 2019;58(3):136-43.

20. Takeuchi Y, Kato M, Kitamura T, Toda D, Taniguchi Y, Shogenji M, et al. Development of Professional Care Program for Nurses in Dementia Wards and Its Educational Effects. Am J Alzheimers Dis Other Demen. 2020;35:1533317520950925. 
21. Swaminathan N, Ravichandran L, Ramachandran S, Milanese S, Singaravelu R, Govindaraj P. Entry level nursing graduate students' perception and readiness toward online component of blended learning: A mixed method study. J Educ Health Promot. 2021;10(1):163.

22. Taylor N, Wyres M, Green A, Hennessy-Priest K, Phillips C, Daymond E, et al. Developing and piloting a simulated placement experience for students. Br J Nurs. 2021;30(13):S19-s24.

23. Meyer K, James D, Amezaga B, White C. Simulation learning to train healthcare students in personcentered dementia care. Gerontol Geriatr Educ. 2020:1-16.

\section{Tables}

Table 1: Student's characteristics

\begin{tabular}{|c|c|}
\hline & Students $(\mathrm{N}=\mathbf{2 8})$ \\
\hline \multicolumn{2}{|l|}{ Age } \\
\hline Mean (SD) & $21.85(2.83)$ \\
\hline Range & $19-32$ \\
\hline \multicolumn{2}{|l|}{ Sex } \\
\hline female $n(\%)$ & $25(89.3)$ \\
\hline \multicolumn{2}{|c|}{ Professional experience in caring for patients with dementia } \\
\hline yes $n(\%)$ & $15(53.6)$ \\
\hline \multicolumn{2}{|c|}{ Number of not participated lectures } \\
\hline $\mathrm{n}=0 \mathrm{n}(\%)$ & $25(89.3)$ \\
\hline Range & $0-1$ \\
\hline
\end{tabular}

Table 2: Evaluation of the course structure 


\begin{tabular}{|lc|}
\hline Course structure aspects & Mean (SD) \\
\hline Course structure was very well. & $1.36(0.48)$ \\
\hline Learning aims were clear defined. & $1.61(0.68)$ \\
\hline Learning contents have been properly demonstrated. & $1.68(0.67)$ \\
\hline Presentations and references are made available. & $1.75(0.88)$ \\
\hline Learning contents had been dealt with appropriate pace. & $1.74(0.94)$ \\
\hline Learning contents were too extensive. & $3.86(0.97)$ \\
\hline Teaching methods contribute to understanding. & $1.63(0.62)$ \\
\hline Teaching contents were up-to-date. & $1.48(0.64)$ \\
\hline Increase of individual learning ability is high. & $2.21(0.99)$ \\
\hline The lecture increases my interest in caring for patients with dementia. & $2.32(1.09)$ \\
\hline
\end{tabular}

$1=$ strongly agree, $2=$ partly agree, $3=$ =neither nor, $4=$ partly disagree, $5=$ disagree

Table 3: Spearman correlation 'course structure aspects'

\begin{tabular}{lcc}
\hline Course structure aspects & SP & $\begin{array}{l}\text { P- } \\
\text { Value }\end{array}$ \\
\hline Course structure was very well. * Learning aims were clear defined. & 0.566 & 0.002 \\
\hline Course structure was very well. * Presentations and references are made available. & 0.514 & 0.005 \\
\hline $\begin{array}{l}\text { Course structure was very well. * Teaching methods contribute to understanding. } \\
\text { Course structure was very well. * Increase of individual learning ability is high. }\end{array}$ & 0.535 & 0.004 \\
\hline $\begin{array}{l}\text { Learning aims were clear defined. * Presentations and references are made } \\
\text { available. }\end{array}$ & 0.573 & 0.001 \\
\hline $\begin{array}{l}\text { Learning contents had been dealt with appropriate pace. * Increase of individual } \\
\text { learning ability is high. }\end{array}$ & 0.000 \\
\hline $\begin{array}{l}\text { Learning contents had been dealt with appropriate pace. * Teaching contents were } \\
\text { up-to-date. }\end{array}$ & 0.588 & 0.000 \\
\hline $\begin{array}{l}\text { Learning contents had been dealt with appropriate pace. * The lecture increases my } \\
\text { interest in caring for patients with dementia. }\end{array}$ & 0.594 & 0.001 \\
\hline
\end{tabular}

Table 4: Docent evaluation 


\begin{tabular}{|l|l|}
\hline Lecturer & Mean (SD) \\
\hline$\ldots$ was well prepared. & $1.18(0.39)$ \\
\hline ... taught structured. & $1.21(0.41)$ \\
\hline ... designed interesting lectures. & $1.86(0.93)$ \\
\hline ... making complicated contents understandable. & $1.64(0.67)$ \\
\hline ... encourage critical discussions. & $2.15(1.02)$ \\
\hline ... was in dealing with students' kind and open-minded. & $1.11(0.42)$ \\
\hline ... was helpful and cooperatively. & $1.21(0.49)$ \\
\hline ... examined issues and suggestions. & $1.14(0.35)$ \\
\hline ... clarified benefits and usability of learning contents. & $1.57(0.69)$ \\
\hline ... gave helpful feedback to the statements made. & $1.54(0.69)$ \\
\hline ... was readily available for further questions. & $1.36(0.56)$ \\
\hline
\end{tabular}

$1=$ strongly agree, 2 =partly agree, $3=$ =neither nor, $4=$ partly disagree, $5=$ disagree

Table 5: Evaluation results of the independent practice on geriatric assessment

\begin{tabular}{|c|c|c|}
\hline Practice on geriatric assessment & Mean (SD) & $1=$ strongly agree, \\
\hline ... had a clearly defined structure. & $1.50(0.51)$ & $\begin{array}{l}2=\text { partly agree, } \\
3=\text { neither nor, }\end{array}$ \\
\hline ... promote the internal learning process. & $1.67(1.00)$ & 4=partly disagree, \\
\hline ... was easy for me. & $2.14(0.89)$ & $5=$ disagree \\
\hline ... had sufficient time. & $1.21(0.41)$ & Table 6: Evaluation \\
\hline ... took previous knowledge up. & $1.68(0.77)$ & $\begin{array}{l}\text { of the online } \\
\text { simulation training }\end{array}$ \\
\hline ... had lot of disruptions, so that I couldn't learn efficiently. & $4.23(1.07)$ & \\
\hline ... had hardly changed my knowledge. & $3.74(1.09)$ & \\
\hline ... had hardly changed my interest in the lecture's theme. & $3.59(1.15)$ & \\
\hline ... had hardly changed my abilities to carry out contents in practice. & $3.70(0.99)$ & \\
\hline
\end{tabular}




\begin{tabular}{|lr|}
\hline The online simulation training & Mean (SD) \\
\hline ... had a clearly defined structure. & $1.39(0.56)$ \\
\hline ... had sufficient time. & $1.08(0.27)$ \\
\hline ... increased my learning motivation. & $2.46(1.20)$ \\
\hline ... took previous knowledge up. & $1.92(0.93)$ \\
\hline ... made lecture contents easier to understand. & $1.86(0.89)$ \\
\hline ... provided specific practical skills. & $2.64(0.99)$ \\
\hline ... enhanced understanding in complex issues. & $2.59(0.93)$ \\
\hline ... I prefer to learn face to face. & $2.46(1.39)$ \\
\hline
\end{tabular}

$1=$ strongly agree, 2 =partly agree, $3=$ =neither nor, $4=$ partly disagree, $5=$ disagree

\section{Figures}
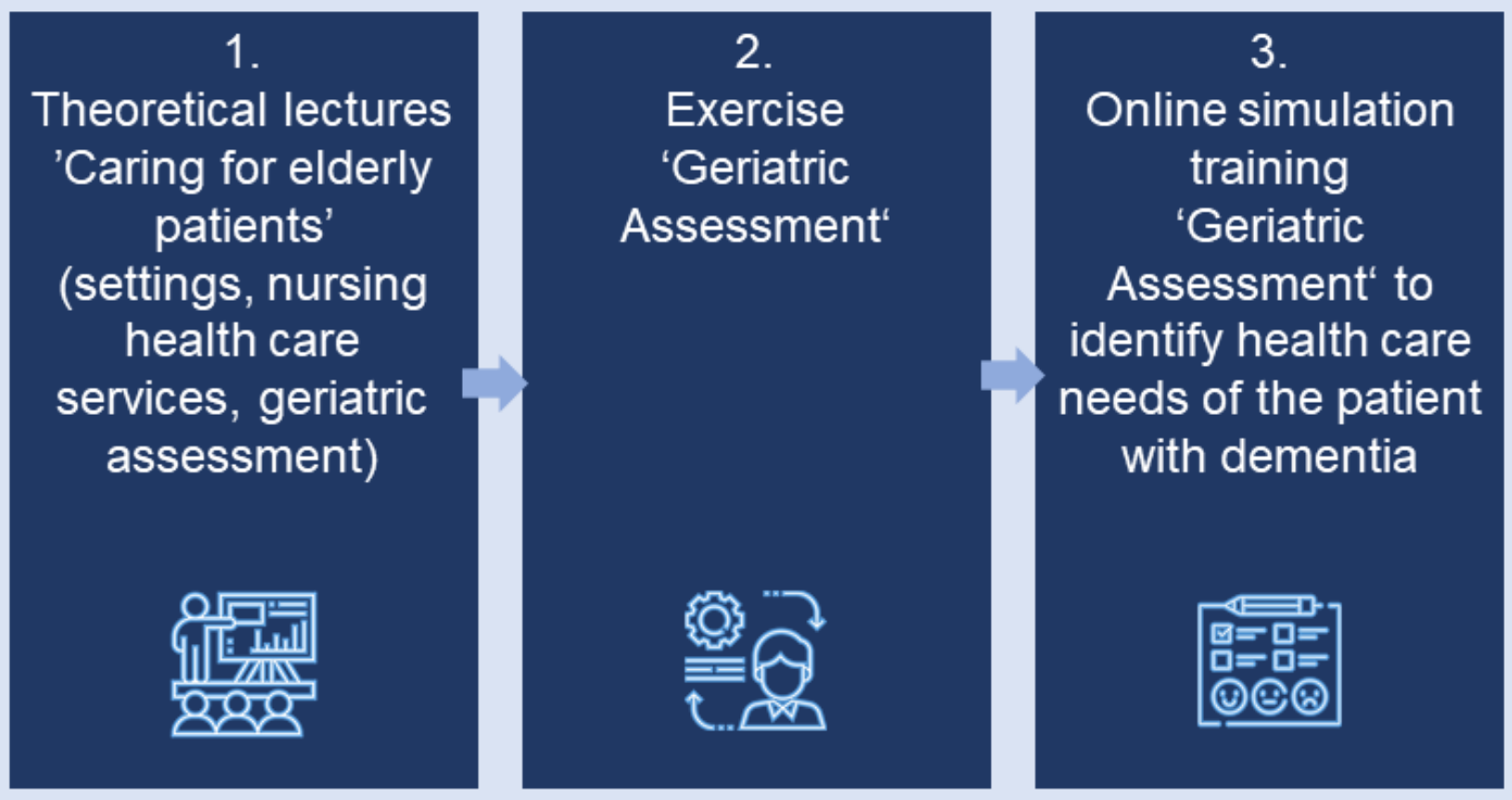

Figure 1 
(a) four theoretical lectures in caring for elderly patients with dementia and the Geriatric Assessment, (b) exercise of Geriatric Assessment and (c) online simulation training (see Figure 1). 